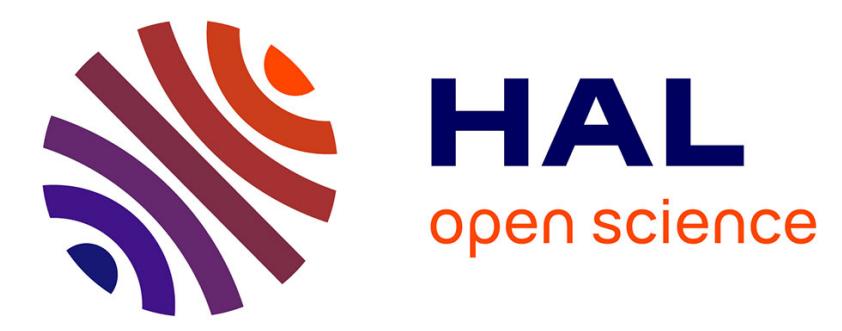

\title{
Near-field observations of light confinement in a two dimensional lithium niobate photonic crystal cavity
}

\author{
J. Dahdah, M.-P. Bernal, N. Courjal, G. Ulliac, F.I. Baida
}

\section{To cite this version:}

J. Dahdah, M.-P. Bernal, N. Courjal, G. Ulliac, F.I. Baida. Near-field observations of light confinement in a two dimensional lithium niobate photonic crystal cavity. Journal of Applied Physics, 2011, 110, pp.074318. 10.1063/1.3647770 . hal-00643748

\section{HAL Id: hal-00643748 \\ https://hal.science/hal-00643748}

Submitted on 30 Apr 2021

HAL is a multi-disciplinary open access archive for the deposit and dissemination of scientific research documents, whether they are published or not. The documents may come from teaching and research institutions in France or abroad, or from public or private research centers.
L'archive ouverte pluridisciplinaire HAL, est destinée au dépôt et à la diffusion de documents scientifiques de niveau recherche, publiés ou non, émanant des établissements d'enseignement et de recherche français ou étrangers, des laboratoires publics ou privés. 


\title{
Near-field observations of light confinement in a two dimensional lithium niobate photonic crystal cavity
}

\author{
Jean Dahdah, ${ }^{\text {a) }}$ Maria Pilar-Bernal, Nadège Courjal, Gwenn Ulliac, and Fadi Baida \\ Institut FEMTO-ST, Dpartement d'optique P.M. Duffieux, UMR 617416 route de Gray, \\ 25030 Besançon cedex, France
}

(Received 27 June 2011; accepted 1 September 2011; published online 14 October 2011)

\begin{abstract}
We report the characterization of a lithium niobate photonic crystal cavity using near field scanning optical microscopy (NSOM) operating in collection scanning mode. The cavity is implemented on an annealed proton exchange waveguide by focused ion beam milling. We observe a confinement of the optical field at the center of the cavity by analyzing the collected light with a probe positioned above the photonic structure. The experimental NSOM results obtained are compared to numerical results obtained by finite difference time domain method. A good agreement is obtained between theoretical and experimental results where a cavity mode appears around $\lambda=1540 \mathrm{~nm}$. (C) 2011 American Institute of Physics. [doi:10.1063/1.3647770]
\end{abstract}

\section{INTRODUCTION}

During the past twenty years, photonic crystals (PhCs) have been attracting much attention, due to their periodic structures that can prevent the propagation of light at certain frequencies. Implementing such photonic crystal structures on a material like lithium niobate $\left(\mathrm{LiNbO}_{3}\right)$, which is strongly sensitive to external phenomena, offers great possibilities of developing ultra-compact active integrated optical components. For instance, electro-optical, acousto-optical or nonlinear $\mathrm{LiNbO}_{3} \quad \mathrm{PhCs}$ have been demonstrated recently with low driving power and with an active length as small as a few tens of microns. ${ }^{1-4}$ These developments were performed by writing a perfectly periodic structure on a bulk $\mathrm{LiNbO}_{3}$ substrate. On the other hand, it has been extensively shown that there is a great interest in introducing a defect inside the periodicity of PhCs (Ref. 5) for achieving a confinement of light at nanometer scale. Integrating such cavities on $\mathrm{LiNbO}_{3}$ substrates would lead to ultra-compact and innovative applications as stopping and trapping of light, ${ }^{6}$ quantum information processing ${ }^{7,8}$ and enhancement of light-matter interactions for sensing applications. ${ }^{9-11}$

If the guiding of light through a $\mathrm{W} 1 \mathrm{LiNbO}_{3}$ photonic waveguide has been demonstrated by near field scanning optical microscopy (NSOM) ${ }^{12}$ there is, however, still a blank concerning defect cavities on $\mathrm{LiNbO}_{3}$ substrates, with high quality factor and small modal volume, despite the obvious appealing perspectives associated with such configurations. Near field optical microscopy has shown to be very efficient and the most commonly used technique for localizing the electromagnetic field confinement inside $\mathrm{PhC}$ cavities. Theoretical and experimental studies has been done on other materials, like $\mathrm{SiO}_{2}$, InP, or GaAs. ${ }^{13-23}$

In this paper, we present a photonic crystal $\mathrm{H} 1$ cavity integrated on a lithium niobate substrate. We show that by

${ }^{\text {a)} E l e c t r o n i c ~ m a i l: ~ j e a n . d a h d a h @ u n i v-f c o m t e . f r . ~}$ using a NSOM in collection mode, the electromagnetic field is confined within the cavity at the resonance wavelength.

\section{WAVEGUIDES AND PHOTONIC CRYSTAL FABRICATION TECHNIQUES}

Similarly to the previously mentioned studies, ${ }^{1,2,12}$ the photonic structures are implemented on $\mathrm{LiNbO}_{3}$ optical waveguide, fabricated by a proton-exchange (APE) process through a $7 \mu \mathrm{m}$ width open line of a silica mask. This step is performed in melted benzoic acid and followed by an annealing step at $333{ }^{\circ} \mathrm{C}$ during $9 \mathrm{~h}$. The geometrical and fabrication parameters of the waveguides have been chosen to make the propagation of the fundamental mode close to the substrate surface while keeping single mode propagation at $\lambda=1.55 \mu \mathrm{m}$. Finally, the sample is diced and the waveguide end facets are polished to achieve a good coupling with the incident beam and to reduce the optical losses. The benefit of the APE waveguides for photonic crystal characterization is that only the TM (H field parallel to the hole axis) waves are guided.

The fabrication of the $\mathrm{PhC}$ structures is then achieved by focused ion beam (FIB) milling. ${ }^{24}$ A 10 to $20 \mathrm{~nm}$ thin chrome layer is deposited on the surface of the sample and grounded with a conductive paste to avoid charging effects during the process. Our FIB is a dual beam Orsay Physics Canion 31/LEO 4400. The system used to command the beam deflection is a Raith Elphy Quantum 4.0. The current and $\mathrm{Ga}+$ ions energy values used for the $\mathrm{LiNbO}_{3}$ sputtering are, respectively, $80 \mathrm{pA}$ and $30 \mathrm{keV}$. Finally, the remaining chrome layer is removed using a chromium etchant type 1020 which contains $6 \%$ of nitric acid and $16 \%$ of ceric ammonium nitrate. The cavity consists of an hexagonal lattice of $18 \times 9$ circular holes with a radius of $r=263 \mathrm{~nm}$ and a periodicity of $a=653 \mathrm{~nm}$, and where the center hole is removed. The total milling time, for the array described above, is of the order of $4 \mathrm{~h}$. The geometrical parameters of 


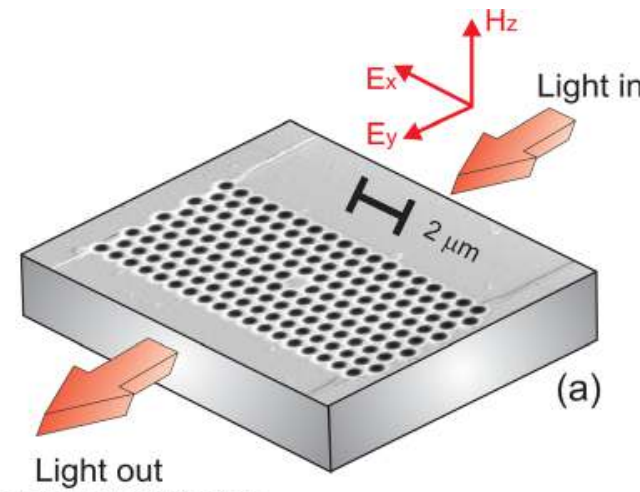

Far Field transmission

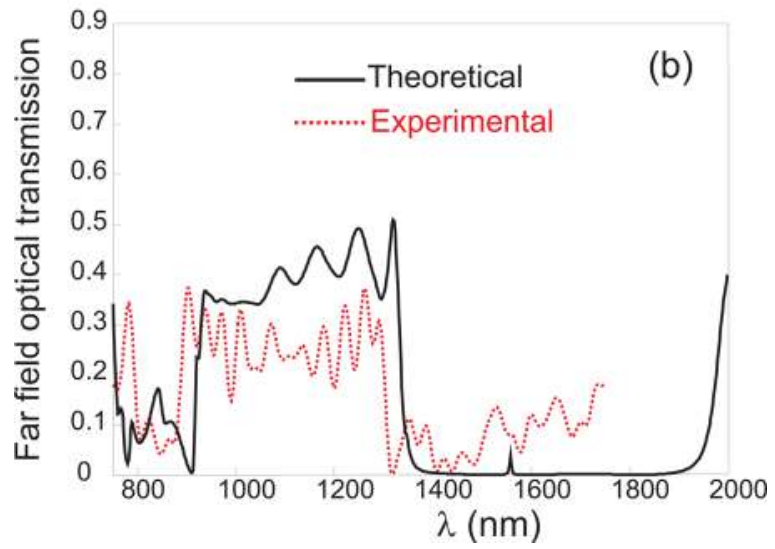

FIG. 1. (Color online) (a) Far field characterization through the photonic structure. (b) Comparison between theoretical (solid line) and experimental (dashed line) results.

the cavity were chosen to obtain a resonance mode at $\lambda=1.55 \mu \mathrm{m}$.

\section{FAR FIELD: THEORETICAL AND EXPERIMENTAL RESULTS}

First, simulations are made to determine the far field transmission response through the $\mathrm{PhC}$ and the spatial distribution of the electromagnetic field in the structure for the guiding conditions described above using a 2D-finite difference time domain (FDTD) homemade code. In order to faithfully model the holes, we use a subgridding technique. ${ }^{11}$ Simulations are made for the TM polarization and for the $\Gamma \mathrm{M}$ direction of propagation (see Figure 1(a)). The theoretical transmission spectrum through the cavity (black curve) is shown in Figure 1(b), where a resonance mode appears at $\lambda=1550 \mathrm{~nm}$ with an amplitude less then $10 \%$. This result explains why there has not been any experimental measurement of transmission resonance peak through $\mathrm{LiNbO}_{3} \mathrm{PhC}$ cavities until now. The origin of the small amplitude of the peak is the small coupling between the cavity mode and the optical mode of the APE waveguide, which full width at half maximum is of $8 \mu \mathrm{m}$.

The experimental study begins with the measurement of the optical spectrum through the $\mathrm{PhC}$ with a supercontinuum source and an optical spectrum analyser (OSA) (Advantest 8381A). The resulting normalized experimental transmission through the PhC cavity is displayed in Figure 1(b) (dashed curve): it shows a gap beginning at $1350 \mathrm{~nm}$. The end of the bang gap cannot be measured, due to the operational wavelength range of the OSA, which does not exceed $1750 \mathrm{~nm}$. It can be seen in the figure that the experimental transmission response coincides rather well with the theoretical predictions (black curve). The experimental results revealed a 30 $\mathrm{nm}$ blue shift in comparison with the theoretical simulations, which may be due to an enlargement of the holes at the surface of the substrate during the FIB milling process. As previously predicted, the transmission peak of the cavity mode is missing. Nevertheless, according to the theoretical spatial distribution of the electromagnetic field shown in Figures 2(a) and 2(b), the energy is predicted to be confined at the defect region for the resonance wavelength $\lambda=1550 \mathrm{~nm}$.

\section{NEAR FIELD: THEORETICAL AND EXPERIMENTAL (SNOM) RESULTS}

The NSOM measurements are performed with the experimental setup shown in Figure 3. The instrument is a commercial NT-MDT SMENA collection mode NSOM which uses a single mode fiber as an optical probe fabricated by heating with a $\mathrm{CO}_{2}$ laser. The evanescent field is coupled to the guided mode of the fiber. To keep a constant distance between the tip and the sample surface we use a non-optical (piezo-electrical line) shear force feedback. The sample was illuminated with a PHOTONETICS tunable laser (1520-1580 $\mathrm{nm})$. The sample and the input fiber were mounted on the XYZ translation stages with 3 tilted angles taking advantage of their sub-micrometer positioning capability.

The sample (Figure 4(a)) is illuminated by the laser source in the $\Gamma \mathrm{M}$ direction as displayed in Figure 1(a). Then, we directly map the electromagnetic field distribution

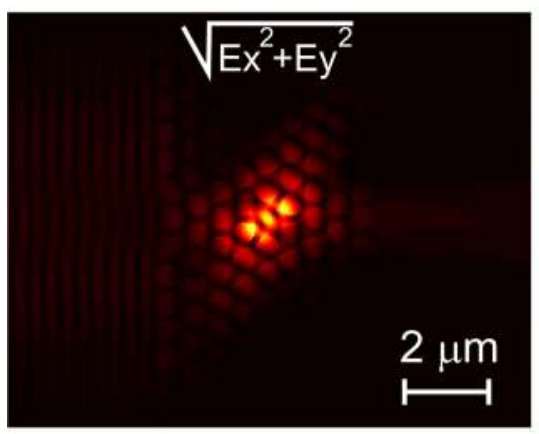

(a)
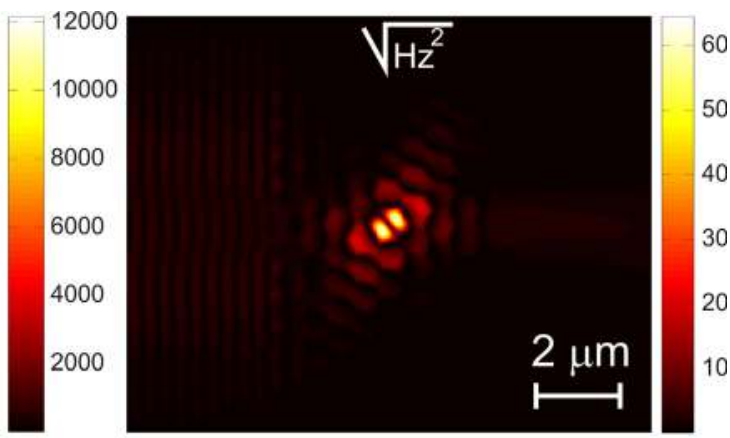

(b)
FIG. 2. (Color online) Electric (a) and magnetic (b) field distribution in the photonic crystal cavity at $\lambda=1550 \mathrm{~nm}$. 


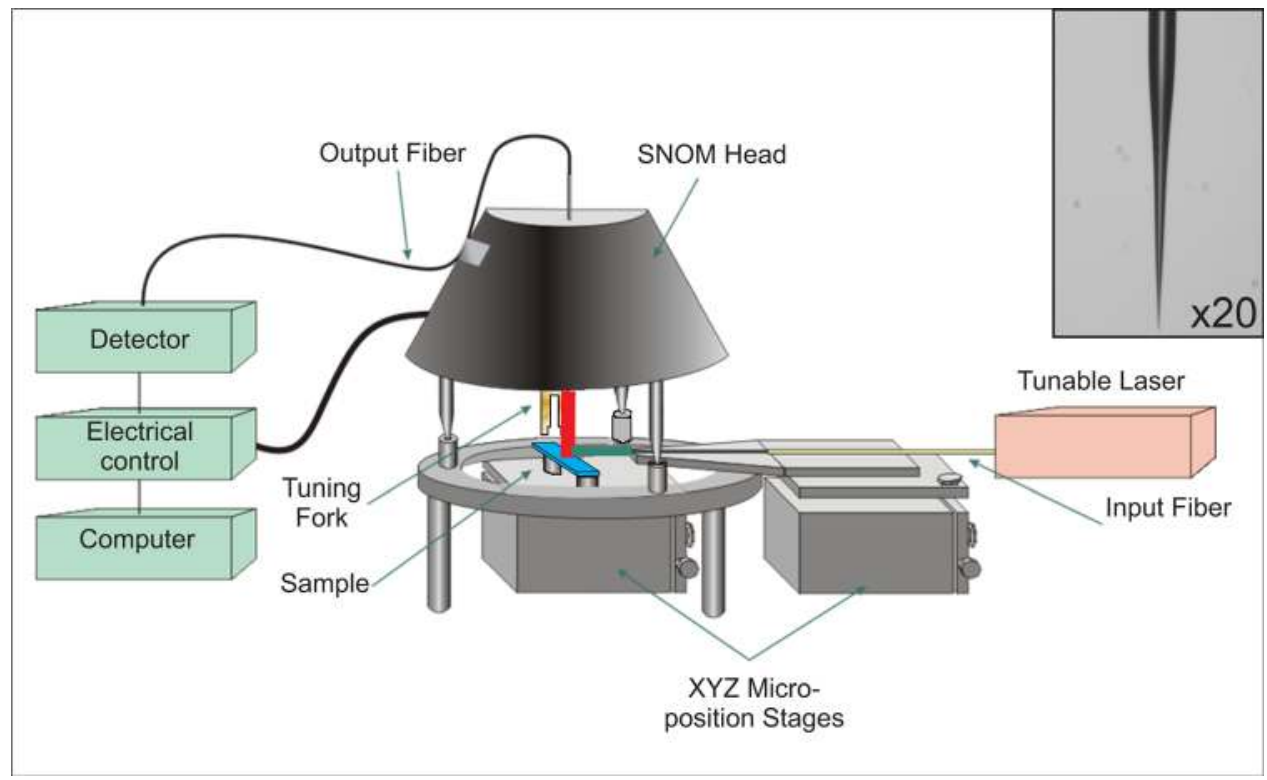

FIG. 3. (Color online) Experimental setup for the NSOM measurements in collection mode with an optical micrograph of the tip used in NSOM setup (right).

at a few nanometers above the sample surface. Near field intensity distributions have been recorded for different excitation wavelengths. Results show a maximum intensity at $\lambda=1540 \mathrm{~nm}$, and it appears that there is still a light confinement within the cavity zone at $1520 \mathrm{~nm}$ or $1560 \mathrm{~nm}$. To understand this experimental observation we have to mention that the theoretical quality factor of the studied cavity has been estimated to be $Q=450$ from FDTD calculations, meaning that the resonance peak is not sharp. The conical shape of the holes is responsible for additional degradation of the quality factor. Taking the above considerations into account, we can conclude from Figure 4(d) that the resonance behavior of the cavity is confirmed, but with a low $(<450)$ quality factor. These results should be improved with the development of well confined $\mathrm{LiNbO}_{3}$ waveguides and with holes exhibiting more vertical walls.

The near-field optical map recorded at $1540 \mathrm{~nm}$ is shown in Figures 4(c) and 4(d). A qualitative comparison between Figures 4(c) and 4(b) shows that the experimental result is in good agreement with the theoretical predictions at the resonance wavelength: the bright spot located at the center of the cavity with the maximum intensity can be advantageously compared to the cavity mode represented in Figure 4(b). Six other spots less bright are observed around the center one, which correspond to the electric field in the holes that surround the defect. A distinction appears where the two lobes surrounding the cavity and the two lobes along the optical waveguide in the experimental image are less intense than the theoretical predictions. This difference can be explained by calculating the convolution between the computed distribution of the calculated electric field (Figure 4(b)) with a gaussian shape describing the near field probe with a diameter of about $175 \mathrm{~nm}$. The predicted distribution of the electric field convoluted with the probe is shown in Figures 5(a) and 5(b). From this figures, we can see that the ratio between the maximum intensity (point b1 of Figure 5(b)) and the intensity at the first side lobe (point b2) is $\frac{I_{b 1}}{I_{b 2}}=6.7$, which is in good agreement with the experimental ratio $\frac{I_{a 1}}{I_{a 2}}=6.27$ measured from the intensities of points a1 and a2 (Figure 4(b)). We also compare the experimental full wave at half maximum, $\mathrm{FWHM}_{\text {exp }}=700 \mathrm{~nm}$ obtained for $\Gamma \mathrm{K}$ section and the theoretical one $\mathrm{FWHM}_{t h}=644 \mathrm{~nm}$ obtained from the convolution results at the resonance wavelength represented in Figure 5(c). In addition, $\Gamma \mathrm{M}$ sections are also compared between the experimental and the convoluted distribution and results are shown in Figure 5(d), where FWHM $_{\text {exp }}=715 \mathrm{~nm}$ and the theoretical one is about 734 nm.
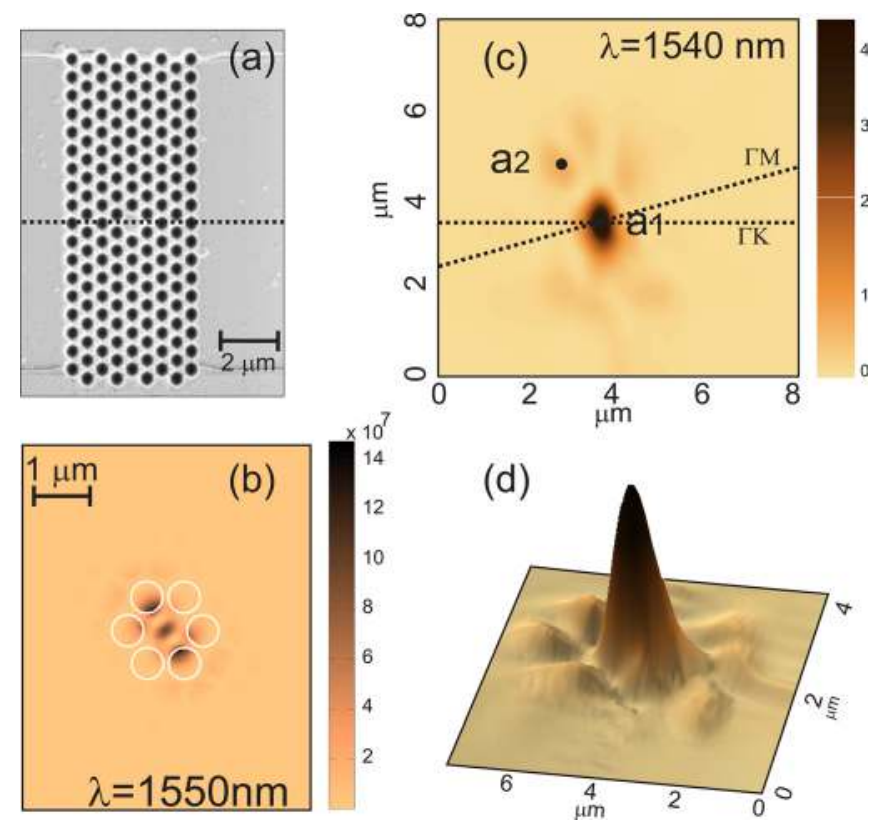

FIG. 4. (Color online) (a) SEM image of the H1 cavity with a period $\mathrm{a}=653 \mathrm{~nm}$ and a radius $\mathrm{r}=263 \mathrm{~nm}$. (b) Electric field distribution obtained by FDTD simulations. Two dimensional (c) and three dimensional (d) optical near field images of the studied structure at the defect region. 

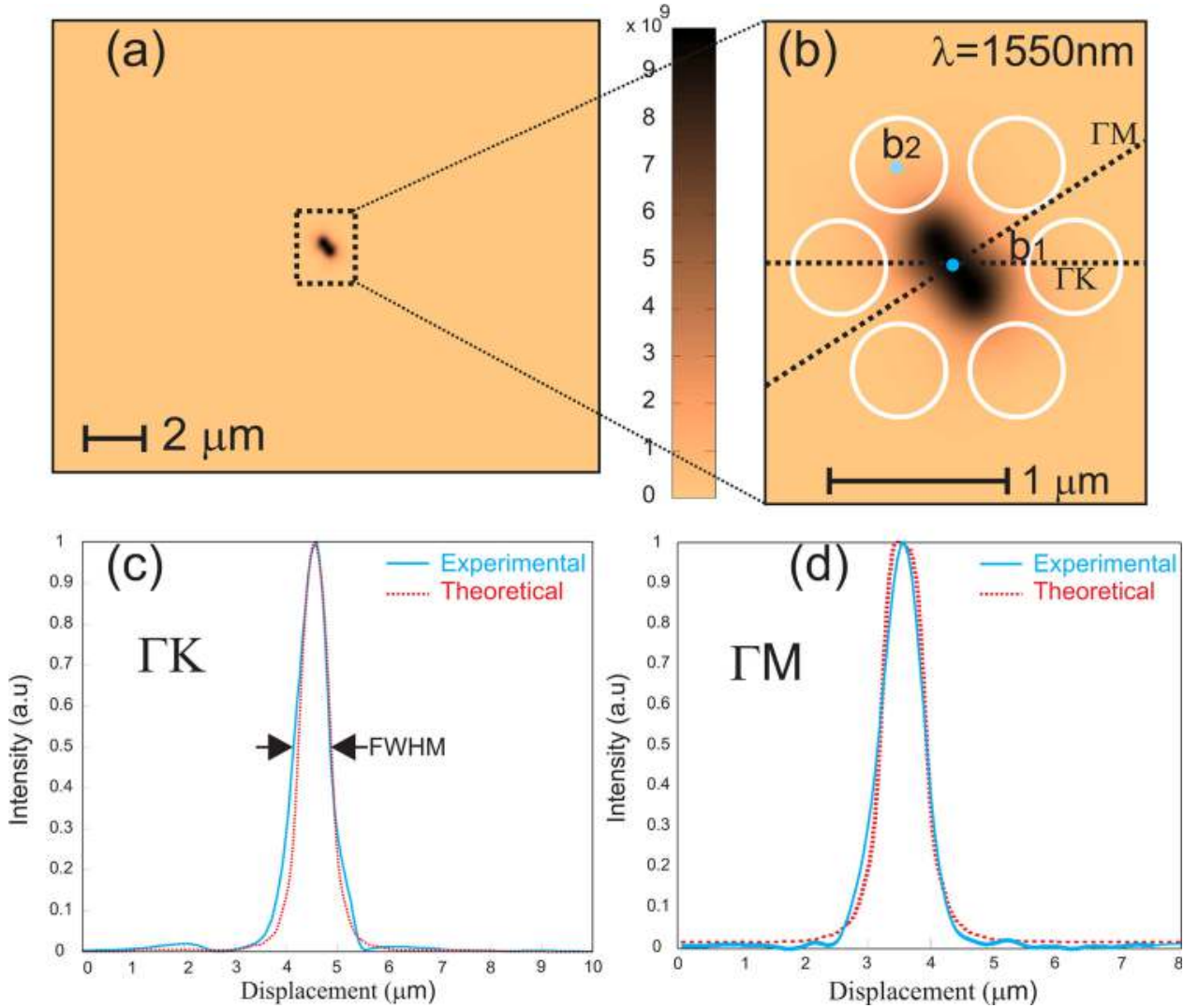

FIG. 5. (Color online) (a) and (b) Electric field distribution obtained by FDTD simulations and convoluted with a gaussian shape with a $F W H M=175 \mathrm{~nm}$. Comparison between theoretical (dashed curve red curve) and experimental (solid curve blue curve) FWHM of the resonance mode for $\Gamma \mathrm{K}$ section (c) and $Г \mathrm{M}$ section (c).

\section{CONCLUSIONS}

In conclusion, we have reported results in far field were the resonance mode is vanished theoretically and experimentally. In addition, in this letter, we reported NSOM measurements of optical fields confined to a subwavelength twodimensional PC-H1 microcavity based on lithium niobate. By comparing our experimental image with the 2D-FDTD simulations, we have observed a clear confinement at the center of the cavity for $\lambda=1540 \mathrm{~nm}$ using the NSOM in collection mode. To enhanced the cavity mode in far field domain, recent FDTD simulations have been done to study the effect of the waveguide width on the transmission ratio of the resonance. Results lead us to recently develop ridge waveguide on a bulk lithium niobate substrate fabricated by optical grade dicing ${ }^{25}$ in order to obtain in very good confinement of the optical mode leading to an importing coupling between the waveguide mode and the photonic crystal cavity.

\section{ACKNOWLEDGMENTS}

The author gratefully thanks Photline Technologies for there support in the fabrication of the APE optical waveguide. We also acknowledge the Conseil Régional de Franche-Comté for financial support under Grant No. 74SB.

${ }^{1}$ M. Roussey, M.-P. Bernal, N. Courjal, D. V. Labeke, F. I. Baida, and R. Salut, Appl. Phys. Lett. 89, 241110 (2006).

${ }^{2}$ N. Courjal, S. Benchabane, J. Dahdah, G. Ulliac, Y. Gruson, and V. Laude, Appl. Phys. Lett. 96, 131103 (2010).
${ }^{3}$ E. H. Barakat, M.-P. Bernal, and F. I. Baida, Opt. Express 18, 6530 (2010).

${ }^{4}$ N. G. R. Broderick, G. W. Ross, H. L. Offerhaus, D. J. Richardson, and D. C. Hanna, Phys. Rev. Lett. 84, 4345 (2000).

${ }^{5}$ E. Yablonovitch, T. J. Gmitter, R. D. Meade, A. M. Rappe, K. D. Brommer, and J. D. Joannopoulos, Phys. Rev. Lett. 67, 3380 (1991).

${ }^{6}$ T. Tanabe, M. Notomi, E. Kuramochi, A. Shinya, and H. Taniyama, Nat. Photonics 1, 49 (2007).

${ }^{7}$ B. Julsgaard, J. Sherson, J. Ignacio Cirac, J. Fiurek, and E. S. Polzik, Nature 432, 482 (2004).

${ }^{8}$ K. Hennessy, A. Badolato, M. Winger, D. Gerace, M. Atatre, S. Gulde, S. Flt, E. L. Hu, and A. Imamoglu, Nature 445, 896 (2007).

${ }^{9}$ M. Lee and P. Fauchet, Opt. Express 15, 4530 (2007).

${ }^{10}$ T. Sunner, T. Stichel, S.-H. Kwon, T.W. Schlereth, S. Hofling, M. Kamp, and A. Forchel, Appl. Phys. Lett. 92, 261112 (2008).

${ }^{11}$ J. Dahdah, N. Courjal, and F. I. Baida, J. Opt. Soc. Am. B 27, 305 (2010).

${ }^{12}$ M.-P. Bernal, N. Courjal, J. Amet, M. Roussey, and C. Hou, Opt. Commun. 265, 180 (2006).

${ }^{13}$ D. Gérard, L. Berguiga, F. de Fornel, L. Salomon, C. Seassal, X. Letartre, P. Rojo-Romeo, and P. Viktorovitch, Opt. Lett. 27, 173 (2002).

${ }^{14}$ K. Okamoto, M. Loncar, T. Yoshie, A. Scherer, Y. Qiu, and P. Gogna, Appl. Phys. Lett. 82, 1676 (2003).

${ }^{15}$ B. Cluzel, D. Gerard, E. Picard, T. Charvolin, V. Calvo, E. Hadji, and F. de Fornel, Appl. Phys. Lett. 85, 2682 (2004).

${ }^{16}$ P. Kramper, M. Agio, C. M. Soukoulis, A. Birner, F. Müller, R. B. Wehrspohn, U. Gösele, and V. Sandoghdar, Phys. Rev. Lett. 92, 113903 (2004).

${ }^{17}$ P. Kramper, M. Kafesaki, C. M. Soukoulis, A. Birner, F. Müller, U. Gösele, R. B. Wehrspohn, J. Mlynek, and V. Sandoghdar, Opt. Lett. 29, 174 (2004).

${ }^{18}$ B. Cluzel, D. Gerard, E. Picard, T. Charvolin, F. de Fornel, and E. Hadji, J. Appl. Phys. 98, 086109 (2005).

${ }^{19}$ N. Louvion, D. Gérard, J. Mouette, F. de Fornel, C. Seassal, X. Letartre, A. Rahmani, and S. Callard, Phys. Rev. Lett. 94, 113907 (2005).

${ }^{20}$ N. Louvion, A. Rahmani, C. Seassal, S. Callard, D. Gérard, and F. de Fornel, Opt. Lett. 31, 2160 (2006).

${ }^{21}$ I. Cestier, D. Gready, U. Ben-Ami, G. Eisenstein, S. Combrie, Q. Tran, and A. de Rossi, Opt. Express 17, 274 (2009). 
${ }^{22}$ K. Foubert, L. Lalouat, B. Cluzel, E. Picard, D. Peyrade, F. de Fornel, and E. Hadji, Appl. Phys. Lett. 94, 251111 (2009).

${ }^{23}$ B. Cluzel, K. Foubert, L. Lalouat, J. Dellinger, D. Peyrade, E. Picard, E. Hadji, and F. de Fornel, Appl. Phys. Lett. 98, 081101 (2011).
${ }^{24}$ F. Lacour, N. Courjal, M.-P. Bernal, A. Sabac, C. Bainier, and M. Spajer, Opt. Mater. 27, 1421 (2004).

${ }^{25}$ N. Bodin, B. Guichardaz, G. Ulliac, J. Y. Rauch, B. Sadani, H. H. Lu, and M. P. Bernal, J. Phys. D, 44, 30 (2011) 305101. 